\title{
The effectiveness of technical trading rules in cryptocurrency markets
}

\author{
Shaen Corbet $^{\mathrm{a}, *}$, Veysel Eraslan ${ }^{\mathrm{b}}$, Brian Lucey ${ }^{\mathrm{c}, \mathrm{d}}$, Ahmet Sensoy \\ ${ }^{a}$ DCU Business School, Dublin City University, Dublin 9, Ireland \\ ${ }^{\mathrm{b}}$ Borsa Istanbul, Resitpasa Mahallesi, Tuncay Artun Caddesi, Emirgan, 34467, Istanbul, Turkey \\ ${ }^{\mathrm{c}}$ Trinity Business School, Trinity College Dublin, Dublin 2, Ireland \\ ${ }^{\mathrm{d}}$ University of Sydney Business School, University of Sydney, Sydney, New South Wales, Australia \\ ${ }^{\mathrm{e}}$ Faculty of Business Administration, Bilkent University, Ankara 06800, Turkey
}

\section{A R T I C L E I N F O}

\section{Keywords:}

Bitcoin

Cryptocurrencies

Technical analysis

High frequency trading

Efficient market hypothesis

\begin{abstract}
A B S T R A C T
We analyse various technical trading rules in the form of the moving average-oscillator and trading range break-out strategies to specifically test resistance and support levels and their trading performance using high-frequency Bitcoin returns. Overall, our results provide significant support for the moving average strategies. In particular, variable-length moving average rule performs the best with buy signals generating higher returns than sell signals.
\end{abstract}

\section{Introduction}

The evolution of cryptocurrencies has been the subject of varying research including their role as speculative trading products (Urquhart, 2016; Urquhart, 2017), the presence of inherent bubbles within the sector (Corbet et al., 2018b), substantial price volatility (Katsiampa et al., 2019), pricing efficiency (Sensoy, 2018; Corbet and Katsiampa, 2018; Mensi et al., 2019), broad market behaviour (Feng et al., 2018; Bouri et al., 2018c; Bouri et al., 2018a; Vidal-Tomas et al., 2018; Mensi et al., 2018), price determination and predictability (Bouri et al., 2018b; Giudici and Abu-Hashish, 2019; Panagiotidis et al., 2018), their relationship with other investment asset classes (Corbet et al., 2018d; Liu, 2018) and derivatives (Corbet et al., 2018a; Corbet et al., 2017). The recent studies also revealed a diminishing confidence in cryptocurrency market integrity and identified the presence of potential fraud and criminal behaviour within this system (Gandal et al., 2018; Griffin and Shams, 2018; Corbet et al., 2019). Corbet et al. (2018c) have provided a concise systematic review of the literature associated with cryptocurrency markets at large, noting the presence of a quite gap with regards to trading dynamics, including the performance of trading rules and properties of the returns of this new asset. This is of significant interest when developing research on this new financial product due to some of its unique characteristics including a twenty-four hour, seven-day-a-week trading schedule and the wide variety of exchanges on which the product can be traded, including the presence of a new futures exchange.

There are various studies on the weak-form pricing efficiency of cryptocurrency assets with majority of them rejecting the null hypothesis of efficiency (Brauneis and Mestel, 2018; Nadarajah and Chu, 2017; Wei, 2018). However, none of these works has shown an explicit way of exploiting this inefficiency. In this study, we develop on the work of Brock et al. (1992) and test whether two of the most popular trading rules, in the form of the moving average (MA hereafter) and the trading range break hold for the Bitcoin market using high-frequency trading data. Such analysis further demonstrates the evolution of this asset class, while investigating as to

\footnotetext{
* Corresponding author.

E-mail address: shaen.corbet@dcu.ie (S. Corbet).
} 
whether cryptocurrencies share similar characteristics to other asset classes that have presented evidence of strong support for both strategies, such as equity markets (Brock et al., 1992), futures markets (Raj and Thurston, 1996), foreign exchange markets (Taylor and Allen, 1992) and commodity markets (Marshall et al., 2008; Batten et al., 2018). Overall, our results provide important results for the technical strategies under observation. We find that the variable-length MA is the most beneficial trading strategy to be applied when trading Bitcoin. Further, buy signals are found to generate higher returns than sell signals under the variable-length MA trading conditions, supporting the conclusion that this technical rule present evidence of predictive power in cryptocurrency markets. $^{1}$

\section{Data and methodology}

In this study, we use dollar-denominated Bitcoin close-price data at one-minute intervals from the Bitfinex exchange. We obtain the price data from Kaiko digital asset store. Our dataset covers the period from 1 January 2014 through 25 June 2018 , which represents a period of 2,341,440 min. Using high-frequency data enables analysis of the high-frequency technical trading rules performance. Our one-minute returns are calculated as:

$$
r_{t, m}=\left(\ln r_{t, m}-\ln r_{t, m-1}\right) \mathrm{x} 100
$$

where $r_{t, m}$ is the return for minute $\mathrm{m}$ on trading day $t$. Time periods with no trading activity are determined to be best represented by the last traded price. Table 1 contains full summary statistics for our dataset. The highest one-minute increase in Bitcoin price (46\%) is observed when the price increased from $\$ 455$ to $\$ 664$ in less than one-minute. The skewness and kurtosis statistics indicate that returns are positively biased and have a leptokurtic distribution.

MA-oscillators and trading range break-out technical rules are usually used to analyse resistance and support levels. According to the MA rule, buy and sell signals are generated by a long-period simple MA and short-period simple MA of prices. We express this strategy as buying (selling) when the short-period ( $S$ minutes) MA rises above (falls below) the long-period ( $L$ minutes, $L>S$ ) MA. Penetration of long-period MAs by short-period MAs is considered to indicate that a trend has started. In this study, we use differing lengths of MAs to investigate both short- and long-periods. ${ }^{2}$ In order to eliminate 'whiplash' signals we also use a band to reduce the number of buy and sell signals. ${ }^{3}$ The MA rule is tested both with and without a $1 \%$ band. This method is best formalised as the following:

$$
\begin{aligned}
& {\left[\sum_{\lambda=1}^{S} P_{t-(\lambda-1) / S}\right]>\left[\sum_{\lambda=1}^{L} P_{t-(\lambda-1) / L}\right]+\text { band } \Rightarrow \text { buy at time } \mathrm{t}} \\
& {\left[\sum_{\lambda=1}^{S} P_{t-(\lambda-1) / S}\right]<\left[\sum_{\lambda=1}^{L} P_{t-(\lambda-1) / L}\right]-\text { band } \Rightarrow \text { sell at time } \mathrm{t}}
\end{aligned}
$$

This method attempts to simulate a strategy where traders go long as the short-MA moves above the long and short when it is below. With a band of zero this method classifies all minutes into either buys or sells, best denoted as variable length MA (VMA). Another variation of this rule is fixed length MA (FMA) which underlines the intersection of MAs. It is considered that returns should be different for some minutes following the crossover. According to FMA, a buy (sell) strategy is generated when the short-MA intercepts the long-MA from below (above). Returns during the next $n$-minute are recorded. Other signals during this $n$-minute period are ignored $(n=10,20,30,60,90,120,180,360,720,1440)$.

The final technical trading rule is based on the resistance and support levels. This rule is called trading range break-out (TRB), where a buy (sell) signal is generated when the price penetrates resistance (support) level. A resistance (support) level is defined as the local maximum (minimum) of the price, computed over the preceding $n$-minute price levels. We also examine $n$-minute holding period returns following buy and sell signals as we do in FMA method. Returns during the next $n$-minute are recorded. We use a band technique where the price must exceed the local maximum by one percent, or fall below the minimum by one percent. The TRB method is formalised as follows:

$$
\begin{aligned}
& P_{t}>\max \left(P_{t-1}, \ldots, P_{t-n}\right)+\text { band } \Rightarrow \text { buy at time } \mathrm{t} \\
& P_{t}<\min \left(P_{t-1}, \ldots, P_{t-n}\right)-\text { band } \Rightarrow \text { sell at time } \mathrm{t}
\end{aligned}
$$

Bonferroni adjusted results are presented in this analysis. To cater the multiple hypothesis problem, we adjust the significance level using the Bonferroni correction, which leads to a significance level of $0.1 \%$. The generalised Bonferroni method adjusts the significance level such that hypothesis $H_{0,(i)}, i=1, \ldots, s$, is deemed rejected if and only if: $\hat{p}_{(i)} \leq \alpha_{(i)} \equiv k \times \alpha / s$. This procedure has the advantage of being robust to the dependence structure of the hypothesis tests.

\footnotetext{
${ }^{1}$ In their working paper, Detzel et al. (2019) also test some of the technical trading rules on Bitcoin, however their scope is low frequency (in terms of 1 to 20 weeks) whereas we are mainly focused on intraday high frequency analysis.

${ }^{2}$ Short-period averages include 1, 2, 5 and 10min MAs and the long-period averages are best represented by the 5, 10, 20, 50, 100, 150 and 200min MAs.

${ }^{3}$ Whiplash signals occur when a security price moves sideways instead of moving in clear trends. The indicator then falsely indicates that trends are forming and generates buy and sell signals accordingly.
} 
Table 1

\begin{tabular}{ll} 
Summary statistics for one-minute Bitcoin returns. \\
\hline Mean & $0.000195 \%$ \\
Max & $46 \%$ \\
Min & $-21.687 \%$ \\
St.Dev & $0.145 \%$ \\
Skewness & 12.385 \\
Kurtosis & 5159.150 \\
No. of Obs. & $2,341,440$
\end{tabular}

\section{Empirical results}

\subsection{The moving average strategy}

Results from VMA strategy are presented in Table 2. We change the rules based on the duration under investigation and by the size of the band. ${ }^{4}$ Analysing forty-eight differing scenarios, we divide the entire sample as a buy or sell period depending on the relative position of the MA. When the short-MA is above (below) the long-MA, the minute is classified as a buy (sell). In Table 2, ' $\mathrm{N}$ (Buy)' and 'N(Sell)' represent the number of buy and sell signals reported during the sample. 'Buy' and 'Sell' indicate the mean number of buy and sell conditions observed. 'Buy $>0$ ' and 'Sell $>0$ ' indicate the proportion of buy and sell returns that are greater than zero. 'Buy-sell' presents the difference between mean buy and sell returns, providing values for all rules except for the tests $(10,20,0.01),(10,50,0.01),(10,100,0.01),(10,150,0.01),(10,200,0.01)$ which are found to be positive and significant. Forty-three out of forty-eight tests are significant at $1 \%$ significance level, rejecting the null hypothesis of being equal to zero. The introduction of $1 \%$ bands increases the spread between mean buy and mean sell returns in each scenario. The average spread without a band is $0.0224 \%$ while the average with a $1 \%$ band is $0.2637 \%$. In most of the cases, buy-sell differences are higher when the short period MA is either a one- or two-minute average.

In Table 2 we find that in forty-six out of forty-eight tests, the mean buy returns are significantly positive and reject the null hypothesis that returns are equal to one-minute unconditional returns at $5 \%$ significance level. Additionally, in forty-two out of fortyeight tests, mean sell returns are significantly negative and reject the null hypothesis that returns are equal to 1-minute unconditional returns at $5 \%$ significance level. Considering all forty-eight tests, average buy return is $0.072 \%$ and average sell return is - $0.071 \%$. The minimum of significant buy returns is higher than unconditional one-minute average return. In Table 2 we find that the ratio of buys and sells is greater than zero. This ratio ranges from $33 \%$ to $94 \%$ for buys and $7 \%$ to $48 \%$ for sells. Moreover, the ratio of buy returns greater than zero is larger than that of sell returns in forty-four tests. Under the null hypotheses that technical rules do not produce useful signals, it is determined that the fraction of positive returns should be the same for both buys and sells, however these differences are found to be highly significant and we can reject the null hypothesis of equality.

We present the results of FMA strategy in Table 3. In this strategy, we examine $n$-minute holding periods after crossing two MAs. The FMA includes forty-eight different tests for each holding period which indicates that there are 480 tests in total. Buy-sell differences are positive for eighty-seven tests and only twenty-one of them are significant at $5 \%$ significance level. Buy-sell differences are not significant for 346 tests and we cannot reject the null hypothesis that returns are equal to $n$-minute unconditional returns at 5\% significance level. Parallel with the results of VMA, in most of the cases where the buy-sell difference is positive, the short-MA is the 1- or 2min MA. Using a band changes the results also for FMA strategy. The average difference without a band is $-0.0428 \%$ while the average with a one percent band is $-0.0135 \%$. The averages of the holding period buy and sell returns are $0.0643 \%$ and $0.0932 \%$ respectively.

\subsection{Trading range break (TRB) strategy}

The results for the TRB strategy are presented in Table 4. According to this strategy buy and sell signals are generated when the price moves above or below local maximums and minimums. In this strategy we use 20 different tests. Local maximums and minimums are calculated from the preceding $n$-minute price levels. After identifying the buy and sell signals, we compute $n$-minute holding period returns.

The second column of the Table 4 represents the preceding $n$-minute period and band length. For example, $(1,120,0.01)$ indicates that local maximums and minimums are calculated from the preceding $120 \mathrm{~min}$ price levels and the band is one percent. The buy-sell difference is positive for four tests and only one is significant at $5 \%$ significance level. Out of sixteen tests where buy-sell difference is negative, eleven of them are significant. The average of the buy-sell difference is $-0.1245 \%$. The average difference without a band is $0.0138 \%$ while the average with a one percent band is $-0.2627 \%$. For six out of twenty rules, buy returns are positive and significantly different from the unconditional $n$-minute return at the $5 \%$ level. All the sell returns except one are greater than zero. The average of buy returns is $0.0872 \%$ while the average of sell returns is $0.2116 \%$.

Overall, our results show that if an investor buys a bitcoin at the beginning of our sample period and holds it until the end of our sample period, the return performance per minute would be the mean one-minute return represented in Table 1 , which is $0.000195 \%$;

\footnotetext{
${ }^{4}$ For example, $(1,100,0)$ indicates that the short period is $1 \mathrm{~min}$, the long period is $100 \mathrm{~min}$ and the band is $0 \%$.
} 
Table 2

Standard test results for the variable-length moving (VMA) rules.

\begin{tabular}{|c|c|c|c|c|c|c|c|}
\hline Test & $\mathrm{N}$ (buy) & $\mathrm{N}(\mathrm{sell})$ & Buy & Sell & Buy $>0$ & Sell $>0$ & Buy-Sell \\
\hline$(1,5,0)$ & $1,059,540$ & $1,093,435$ & $0.0517^{* * *}$ & $-0.0497^{* * *}$ & 0.5731 & 0.1430 & $0.1014 * * *$ \\
\hline$(1,10,0)$ & $1,166,187$ & $1,129,154$ & $0.0363^{* * *}$ & $-0.0371^{* * *}$ & 0.4662 & 0.1959 & $0.0734 * * *$ \\
\hline$(1,20,0)$ & $1,194,244$ & $1,135,958$ & $0.0268^{* * *}$ & $-0.0278^{* * *}$ & 0.4180 & 0.2342 & $0.0546^{* * *}$ \\
\hline$(1,50,0)$ & $1,201,811$ & $1,137,695$ & $0.0182^{* * *}$ & $-0.0188^{* * *}$ & 0.3826 & 0.2686 & $0.0370^{* * *}$ \\
\hline$(1,100,0)$ & $1,208,326$ & $1,132,400$ & $0.0134 * * *$ & $-0.0139 * * *$ & 0.3656 & 0.2857 & $0.0272^{* * *}$ \\
\hline$(1,150,0)$ & $1,213,068$ & $1,127,781$ & $0.0111^{* * *}$ & $-0.0115^{* * *}$ & 0.3585 & 0.2930 & $0.0226^{* * *}$ \\
\hline$(1,200,0)$ & $1,215,547$ & $1,125,662$ & $0.0098^{* * *}$ & $-0.0101^{* * *}$ & 0.3543 & 0.2973 & $0.0199 * * *$ \\
\hline$(2,5,0)$ & $1,059,096$ & $1,095,167$ & $0.0289^{* * *}$ & $-0.0275^{* * *}$ & 0.4603 & 0.2288 & $0.0564 * * *$ \\
\hline$(2,10,0)$ & $1,164,327$ & $1,129,951$ & $0.0188^{* * *}$ & $-0.0190^{* * * *}$ & 0.4129 & 0.2617 & $0.0379 * * *$ \\
\hline$(2,20,0)$ & $1,193,457$ & $1,136,666$ & $0.0129^{* * *}$ & $-0.0131^{* * *}$ & 0.3712 & 0.2835 & $0.0260^{* * * *}$ \\
\hline$(2,50,0)$ & $1,201,594$ & $1,137,898$ & $0.0081^{* * *}$ & $-0.0081^{* * *}$ & 0.3519 & 0.3010 & $0.0162^{* * *}$ \\
\hline$(2,100,0)$ & $1,208,144$ & $1,132,582$ & $0.0056^{* * *}$ & $-0.0056^{* * *}$ & 0.3433 & 0.3096 & $0.0113^{* * *}$ \\
\hline$(2,150,0)$ & $1,213,025$ & $1,127,827$ & $0.0046^{* * *}$ & $-0.0045^{* * *}$ & 0.3401 & 0.3128 & $0.0091^{* * *}$ \\
\hline$(2,200,0)$ & $1,215,280$ & $1,125,929$ & $0.0039 * * *$ & $-0.0039 * * *$ & 0.3379 & 0.3150 & $0.0078^{* * *}$ \\
\hline$(5,20,0)$ & $1,192,031$ & $1,135,522$ & $0.0056^{* * *}$ & $-0.0054^{* * *}$ & 0.3468 & 0.3098 & $0.0110^{* * * *}$ \\
\hline$(5,50,0)$ & $1,201,121$ & $1,138,308$ & $0.0031^{* * *}$ & $-0.0029^{* * *}$ & 0.3362 & 0.3176 & $0.0060^{* * *}$ \\
\hline$(5,100,0)$ & $1,207,756$ & $1,133,162$ & $0.0020^{* * * *}$ & $-0.0017^{* * *}$ & 0.3321 & 0.3215 & $0.0037^{* * *}$ \\
\hline$(5,150,0)$ & $1,212,804$ & $1,128,045$ & $0.0015^{* * *}$ & $-0.0012^{* * *}$ & 0.3309 & 0.3227 & $0.0027^{* * *}$ \\
\hline$(5,200,0)$ & $1,215,042$ & $1,126,166$ & $0.0012^{* * *}$ & $-0.0009^{* * *}$ & 0.3299 & 0.3236 & $0.0021^{* * *}$ \\
\hline$(10,20,0)$ & $1,187,377$ & $1,137,978$ & $0.0031^{* * *}$ & $-0.0028^{* * *}$ & 0.3386 & 0.3190 & $0.0058^{* * *}$ \\
\hline$(10,50,0)$ & $1,199,823$ & $1,138,844$ & $0.0016^{* * *}$ & $-0.0013^{* * *}$ & 0.3315 & 0.3228 & $0.0029 * * *$ \\
\hline$(10,100,0)$ & $1,206,524$ & $1,134,050$ & $0.0010^{* * *}$ & $-0.0006^{* * *}$ & 0.3290 & 0.3248 & $0.0016^{* * *}$ \\
\hline$(10,150,0)$ & $1,212,656$ & $1,128,189$ & 0.0006 & $-0.0002^{* * *}$ & 0.3281 & 0.3257 & $0.0008^{* * *}$ \\
\hline$(10,200,0)$ & $1,214,782$ & $1,126,340$ & 0.0005 & $-0.0001^{* * *}$ & 0.3278 & 0.3259 & $0.0006^{* * *}$ \\
\hline Test & N(buy) & $\mathrm{N}($ sell $)$ & Buy & Sell & Buy $>0$ & Sell $>0$ & Buy-Sell \\
\hline$(1,5,0.01)$ & 2253 & 2595 & $1.0384 * * *$ & $-1.0114^{* * *}$ & 0.9419 & 0.0728 & $2.0498^{* * *}$ \\
\hline$(1,10,0.01)$ & 7354 & 8416 & $0.5016^{* * *}$ & $-0.5117^{* * *}$ & 0.8283 & 0.1501 & $1.0133^{* * *}$ \\
\hline$(1,20,0.01)$ & 18,319 & 20,314 & $0.2559 * * *$ & $-0.2665^{* * *}$ & 0.7218 & 0.2426 & $0.5225^{* * *}$ \\
\hline$(1,50,0.01)$ & 51,282 & 54,284 & $0.1087^{* * *}$ & $-0.1167^{* * *}$ & 0.6067 & 0.3288 & $0.2255^{* * *}$ \\
\hline$(1,100,0.01)$ & 98,778 & 99,862 & $0.0571^{* * *}$ & $-0.0631^{* * *}$ & 0.5412 & 0.3660 & $0.1202^{* * *}$ \\
\hline$(1,150,0.01)$ & 139,463 & 136,400 & $0.0401^{* * *}$ & $-0.0443^{* * *}$ & 0.5120 & 0.3777 & $0.0844^{* * * *}$ \\
\hline$(1,200,0.01)$ & 173,484 & 165,519 & $0.0315^{* * *}$ & $-0.0348^{* * *}$ & 0.4942 & 0.3852 & $0.0663^{* * *}$ \\
\hline$(2,5,0.01)$ & 818 & 1020 & $0.6313^{* * * *}$ & $-0.6264^{* * *}$ & 0.5961 & 0.2833 & $1.2577^{* * *}$ \\
\hline$(2,10,0.01)$ & 5014 & 5905 & $0.2385^{* * *}$ & $-0.2536^{* * *}$ & 0.5448 & 0.3253 & $0.4920^{* * * *}$ \\
\hline$(2,20,0.01)$ & 15,708 & 17,508 & $0.1154^{* * *}$ & $-0.1185^{* * *}$ & 0.5878 & 0.3741 & $0.2339 * * *$ \\
\hline$(2,50,0.01)$ & 48,850 & 51,688 & $0.0482^{* * *}$ & $-0.0501^{* * *}$ & 0.5299 & 0.4057 & $0.0982^{* * *}$ \\
\hline$(2,100,0.01)$ & 96,718 & 98,037 & $0.0257^{* * *}$ & $-0.0269 * * *$ & 0.4921 & 0.4146 & $0.0526^{* * *}$ \\
\hline$(2,150,0.01)$ & 137,735 & 134,863 & $0.0180^{* * * *}$ & $-0.0184^{* * *}$ & 0.4742 & 0.4161 & $0.0364 * * *$ \\
\hline$(2,200,0.01)$ & 172,020 & 164,202 & $0.0138^{* * *}$ & $-0.0143^{* * *}$ & 0.4631 & 0.4172 & $0.0281 * * *$ \\
\hline$(5,20,0.01)$ & 9448 & 11,019 & $0.0259^{* * *}$ & $-0.0125^{* * *}$ & 0.4942 & 0.4649 & $0.0384 * * *$ \\
\hline$(5,50,0.01)$ & 42,445 & 45,365 & $0.0142^{* * *}$ & $-0.0088^{* * *}$ & 0.4817 & 0.4553 & $0.0230 * * *$ \\
\hline$(5,100,0.01)$ & 91,326 & 93,085 & $0.0078^{* * *}$ & $-0.0058^{* * *}$ & 0.4607 & 0.4454 & $0.0136^{* * *}$ \\
\hline$(5,150,0.01)$ & 133,141 & 130,713 & $0.0055^{* * *}$ & $-0.0037^{* * * *}$ & 0.4510 & 0.4398 & $0.0092^{* * *}$ \\
\hline$(5,200,0.01)$ & 168,083 & 161,004 & $0.0044 * * *$ & $-0.0028^{* * *}$ & 0.4447 & 0.4364 & $0.0072^{* * *}$ \\
\hline$(10,20,0.01)$ & 2553 & 3381 & $-0.0059^{* *}$ & $0.0420 * * *$ & 0.4634 & 0.4812 & $-0.0478^{* * *}$ \\
\hline$(10,50,0.01)$ & 32,573 & 35,258 & $0.0041^{* * *}$ & $0.0041 * * *$ & 0.4665 & 0.4664 & 0.0000 \\
\hline$(10,100,0.01)$ & 82,600 & 85,112 & $0.0018^{* * * *}$ & 0.0009 & 0.4504 & 0.4539 & 0.0009 \\
\hline$(10,150,0.01)$ & 125,848 & 124,186 & $0.0020^{* * * *}$ & 0.0005 & 0.4439 & 0.4458 & 0.0015 \\
\hline$(10,200,0.01)$ & 161,825 & 155,606 & $0.0014^{* * * *}$ & 0.0006 & 0.4381 & 0.4417 & 0.0009 \\
\hline
\end{tabular}

Note: 'N(Buy)' and ' $\mathrm{N}(\mathrm{Sell})$ ' are the number of buy and sell signals reported during the sample. *** indicates statistically significance at the Bonferroni-adjusted $0.1 \%$ level respectively, testing the difference of the mean buy and mean sell from the unconditional 1-minute mean, and buysell from zero.

i.e., 0.00000195. The compare this value with the results of the technical trading, we look at the last columns of Tables 2 and 4 ; and also the results reported in Table 3. Accordingly, depending on the selected technical analysis methodology, technical trading can generate 100 to 10,000 times of returns obtained from buy and hold strategy.

\section{Concluding comments}

A broad number of studies analyse the predictability of financial asset classes based on past returns, yet to date no study has investigated the performance of technical trading rules in cryptocurrency markets. We analyse various popular trading rules in the form of the MA and trading range break strategies and their performance when applied to high-frequency Bitcoin returns. Overall, our results provide significant support for the VMA strategy. Under the VMA strategy, we can reject the null hypothesis that technical rules do not produce useful signals which indicates a break from the condition that the number of buys is equal to sells across a variety of differing frequencies. However, using the FMA, we cannot reject the null hypothesis that returns are equal to the $n$-minute 
Table 3

Buy-sell results for the fixed-length moving (FMA) rules.

\begin{tabular}{|c|c|c|c|c|c|c|c|c|c|c|}
\hline Test & $10 \mathrm{~min}$ & $20 \mathrm{~min}$ & $30 \mathrm{~min}$ & $60 \mathrm{~min}$ & $90 \mathrm{~min}$ & $120 \mathrm{~min}$ & $180 \mathrm{~min}$ & $360 \mathrm{~min}$ & $720 \mathrm{~min}$ & $1440 \mathrm{~min}$ \\
\hline$(1,5,0)$ & $0.0079 * * *$ & $0.0093^{* * *}$ & $0.0134 * * *$ & 0.0143 & -0.0013 & -0.0159 & 0.0483 & -0.0338 & -0.2479 & -0.2035 \\
\hline$(1,10,0)$ & 0.0020 & -0.0012 & 0.0032 & 0.0223 & 0.0195 & 0.0023 & 0.0477 & -0.0813 & 0.0450 & 0.0408 \\
\hline$(1,20,0)$ & $-0.0090^{* * *}$ & -0.0014 & -0.0059 & -0.0134 & -0.0177 & -0.0184 & 0.0098 & 0.0618 & 0.1341 & 0.2808 \\
\hline$(1,50,0)$ & $-0.0154 * * *$ & -0.0113 & -0.0148 & -0.0087 & -0.0507 & -0.0531 & 0.0462 & -0.0808 & -0.2206 & 0.2562 \\
\hline$(1,100,0)$ & $-0.0204^{* * *}$ & -0.0109 & $-0.0189^{*}$ & -0.0143 & -0.0328 & -0.0300 & 0.0054 & -0.1224 & -0.0102 & -0.2426 \\
\hline$(1,150,0)$ & $-0.0199 * * *$ & $-0.0187^{* * *}$ & -0.0177 & -0.0278 & -0.0374 & -0.0424 & -0.0669 & 0.0087 & -0.2021 & -0.3516 \\
\hline$(1,200,0)$ & $-0.0243 * * *$ & $-0.0189 * * *$ & $-0.0281 * * *$ & $-0.0643^{* * *}$ & $-0.0879 * * *$ & $-0.0873^{* * *}$ & -0.1054 & -0.1288 & -0.2485 & -0.4103 \\
\hline$(2,5,0)$ & $0.0082^{* * *}$ & 0.0066 & $0.0125^{* * *}$ & 0.0240 & -0.0075 & -0.0001 & $0.0831^{* * *}$ & 0.0307 & 0.0409 & 0.2881 \\
\hline$(2,10,0)$ & $0.0032^{* * *}$ & -0.0009 & -0.0010 & $0.0270^{* * *}$ & 0.0112 & -0.0261 & 0.0552 & -0.0693 & -0.0424 & 0.0241 \\
\hline$(2,20,0)$ & $-0.0102^{* * *}$ & -0.0021 & -0.0021 & 0.0055 & -0.0436 & -0.0336 & -0.0088 & -0.0483 & -0.0476 & -0.1691 \\
\hline$(2,50,0)$ & $-0.0156^{* * *}$ & $-0.0137^{* * *}$ & -0.0102 & -0.0078 & -0.0273 & -0.0336 & 0.0536 & -0.1349 & -0.0642 & 0.1108 \\
\hline$(2,100,0)$ & $-0.0212^{* * *}$ & $-0.0179 * * *$ & -0.0181 & -0.0151 & -0.0345 & -0.0334 & -0.0254 & -0.0944 & -0.0483 & -0.2534 \\
\hline$(2,150,0)$ & $-0.0250 * * *$ & $-0.0186^{* * *}$ & $-0.0220 * * *$ & $-0.0437 * * *$ & -0.0391 & -0.0398 & -0.0792 & -0.0044 & -0.1990 & -0.1031 \\
\hline$(2,200,0)$ & $-0.0289 * * *$ & $-0.0255^{* * *}$ & $-0.0333^{* * *}$ & $-0.0699 * * *$ & $-0.0998^{* * *}$ & $-0.0918^{* * *}$ & -0.0982 & -0.1561 & -0.1929 & -0.1756 \\
\hline$(5,20,0)$ & $-0.0107^{* * *}$ & -0.0017 & -0.0060 & -0.0144 & -0.0269 & -0.0319 & -0.0409 & -0.0673 & -0.0628 & -0.1714 \\
\hline$(5,50,0)$ & $-0.0136 * * *$ & $-0.0132^{* * *}$ & -0.0093 & -0.0145 & -0.0357 & -0.0391 & -0.0340 & -0.0745 & -0.0071 & -0.0363 \\
\hline$(5,100,0)$ & $-0.0185^{* * *}$ & -0.0116 & -0.0166 & -0.0227 & -0.0334 & -0.0378 & -0.0035 & 0.0195 & -0.0977 & -0.1615 \\
\hline$(5,150,0)$ & $-0.0253^{* * *}$ & $-0.0190^{* * *}$ & $-0.0229 * * *$ & $-0.0415^{* * *}$ & $-0.0623^{* * *}$ & -0.0503 & -0.0923 & -0.0570 & -0.2490 & -0.3627 \\
\hline$(5,200,0)$ & $-0.0248 * * *$ & $-0.0220^{* * *}$ & $-0.0350^{* * *}$ & $-0.0590 * * *$ & $-0.0932^{* * *}$ & $-0.0876^{* * *}$ & $-0.1003^{* * *}$ & -0.1630 & -0.2785 & -0.2750 \\
\hline$(10,20,0)$ & $-0.0094^{* * *}$ & -0.0025 & 0.0008 & -0.0019 & 0.0085 & 0.0019 & -0.0045 & -0.0383 & 0.0824 & -0.0556 \\
\hline$(10,50,0)$ & $-0.0080 * * *$ & -0.0048 & -0.0048 & -0.0082 & -0.0354 & -0.0278 & -0.0412 & -0.0212 & -0.1033 & -0.1431 \\
\hline$(10,100,0)$ & $-0.0121 * * *$ & -0.0025 & $-0.0194 * * *$ & -0.0112 & -0.0196 & -0.0287 & -0.0294 & -0.0124 & -0.1052 & -0.2367 \\
\hline$(10,150,0)$ & $-0.0181^{* * *}$ & $-0.0144 * * *$ & -0.0159 & $-0.0313^{* * *}$ & $-0.0518^{* * *}$ & -0.0506 & -0.0728 & -0.0014 & -0.2611 & -0.2314 \\
\hline$(10,200,0)$ & $-0.0180^{* * *}$ & -0.0109 & $-0.0244^{* * *}$ & $-0.0483^{* * *}$ & $-0.0875^{* * *}$ & $-0.0888^{* * *}$ & $-0.1085^{* * *}$ & -0.1070 & -0.2074 & -0.0473 \\
\hline Test & $10 \mathrm{~min}$ & $20 \min$ & $30 \mathrm{~min}$ & $60 \mathrm{~min}$ & $90 \mathrm{~min}$ & $120 \mathrm{~min}$ & $180 \mathrm{~min}$ & $360 \mathrm{~min}$ & $720 \mathrm{~min}$ & $1440 \mathrm{~min}$ \\
\hline$(1,5,0.01)$ & $-0.3459 * * *$ & -0.2756 & & & & & & & & \\
\hline$(1,10,0.01)$ & $-0.2872 * * *$ & $-0.1998^{* * *}$ & $-0.2160 * * *$ & -0.1734 & -0.1935 & -0.0758 & -0.1703 & -0.2421 & 0.4364 & 1.2235 \\
\hline$(1,20,0.01)$ & $-0.2084^{* * *}$ & $-0.2269 * * *$ & $-0.1522 * * *$ & -0.1636 & -0.1153 & -0.1130 & -0.1887 & -0.1929 & 0.0986 & 1.1907 \\
\hline$(1,50,0.01)$ & $-0.0815^{* * *}$ & $-0.0992^{* * *}$ & $-0.1306^{* * *}$ & $-0.1751^{* * *}$ & -0.1073 & -0.1472 & -0.0756 & -0.1505 & 0.1178 & 0.7180 \\
\hline$(1,100,0.01)$ & $-0.0519 * * *$ & -0.0352 & -0.0456 & -0.0900 & -0.0682 & -0.0992 & -0.1729 & -0.1397 & 0.1254 & 0.7496 \\
\hline$(1,150,0.01)$ & -0.0265 & -0.0218 & -0.0285 & -0.0719 & -0.0803 & -0.1095 & -0.1132 & -0.0990 & -0.0222 & 0.9400 \\
\hline$(1,200,0.01)$ & -0.0104 & -0.0128 & -0.0093 & -0.0220 & -0.0275 & -0.0559 & -0.0761 & -0.2072 & 0.0313 & 0.5155 \\
\hline$(2,5,0.01)$ & $-0.4573^{* * *}$ & -0.1537 & -0.2001 & -0.2223 & -0.3749 & -0.0269 & -0.8776 & -0.7097 & -0.6705 & -0.7055 \\
\hline$(2,10,0.01)$ & $-0.3486 * * *$ & $-0.2058^{* * *}$ & -0.1768 & -0.1461 & -0.1514 & -0.0283 & -0.3523 & -0.1897 & 0.4701 & 1.1819 \\
\hline$(2,20,0.01)$ & $-0.2708^{* * *}$ & $-0.2531^{* * *}$ & $-0.1630 * * *$ & -0.1403 & -0.1501 & -0.2313 & -0.2979 & -0.2417 & 0.2043 & 1.2973 \\
\hline$(2,50,0.01)$ & $-0.1048^{* * *}$ & $-0.1381^{* * *}$ & $-0.1586^{* * *}$ & $-0.1730 * * *$ & -0.1144 & -0.1575 & -0.1136 & -0.1964 & 0.0401 & 1.0403 \\
\hline$(2,100,0.01)$ & $-0.0806^{* * *}$ & -0.0615 & -0.0639 & $-0.1273^{* * *}$ & -0.1244 & -0.1622 & -0.1476 & -0.1421 & 0.1171 & $1.2700 * * *$ \\
\hline$(2,150,0.01)$ & $-0.0467^{* * *}$ & -0.0238 & -0.0260 & -0.0754 & -0.0539 & -0.0799 & -0.1133 & -0.1263 & 0.2273 & $1.4407^{\text {*** }}$ \\
\hline$(2,200,0.01)$ & -0.0302 & -0.0195 & -0.0284 & -0.0462 & -0.0023 & -0.0315 & -0.1006 & -0.1705 & 0.0962 & 0.5318 \\
\hline$(5,20,0.01)$ & $-0.2879 * * *$ & $-0.1774^{* * *}$ & -0.1230 & -0.0838 & -0.1805 & -0.2566 & -0.0616 & -0.2243 & 0.4023 & 1.6251 \\
\hline$(5,50,0.01)$ & $-0.1583^{* * *}$ & $-0.1215^{* * *}$ & $-0.1493^{* * *}$ & $-0.1794 * * *$ & $-0.1937 * * *$ & -0.2413 & -0.1084 & -0.0334 & 0.0551 & 1.2971 \\
\hline$(5,100,0.01)$ & $-0.0989 * * *$ & $-0.0587^{* * *}$ & $-0.0808^{* * *}$ & $-0.1400 * * *$ & -0.1430 & $-0.2058^{* * *}$ & -0.2032 & -0.1372 & 0.2114 & 0.8900 \\
\hline$(5,150,0.01)$ & $-0.0556^{* * *}$ & -0.0348 & -0.0401 & $-0.1017^{* * *}$ & -0.0631 & -0.1229 & -0.1774 & -0.1348 & 0.1707 & 0.6848 \\
\hline$(5,200,0.01)$ & $-0.0548 * * *$ & -0.0348 & -0.0383 & -0.0498 & -0.0279 & -0.0587 & -0.1217 & -0.1175 & 0.1155 & 0.8997 \\
\hline$(10,20,0.01)$ & $-0.2753^{* * *}$ & 0.0658 & -0.0304 & -0.0939 & 0.0958 & 0.0656 & -0.0297 & -0.2939 & 0.1931 & 0.5600 \\
\hline$(10,50,0.01)$ & $-0.1726^{* * *}$ & $-0.1111^{* * *}$ & $-0.1593^{* * *}$ & -0.1443 & -0.1489 & -0.2036 & -0.2331 & -0.3462 & -0.1571 & 1.0394 \\
\hline$(10,100,0.01)$ & $-0.0805^{* * *}$ & -0.0272 & $-0.0871^{* * *}$ & $-0.1303^{* * *}$ & $-0.1719^{* * *}$ & $-0.2766^{* * *}$ & $-0.2801^{* * *}$ & -0.1769 & 0.3700 & $1.3828^{* * *}$ \\
\hline$(10,150,0.01)$ & $-0.0454 * * *$ & -0.0252 & -0.0473 & -0.0717 & -0.0951 & $-0.1565^{*}$ & -0.1334 & -0.0662 & 0.0193 & 0.6593 \\
\hline$(10,200,0.01)$ & -0.0487 & -0.0236 & -0.0509 & -0.0406 & -0.0221 & -0.0712 & -0.1161 & -0.1178 & -0.0160 & 0.4803 \\
\hline
\end{tabular}

Note: $* * *$ indicates statistically significance at the Bonferroni-adjusted $0.1 \%$ level respectively, testing the difference of the mean buy and mean sell from the unconditional $n$-minute mean, and buy-sell from zero. For brevity, only the buy-sell results are presented above. All other results related to the analysis based on FMA rules are available from the authors on request.

unconditional returns at a 5\% level of significance. Finally, according to the TRB strategy, buy signals generally generate negative average returns and sell signals generate positive average returns, which do not provide support to the argument that technical trading rules provide useful signals to Bitcoin investors. Taking all the three different trading strategies (VMA, FMA and TRB) into consideration, we reveal that the VMA is the most beneficial trading strategy to be applied when trading Bitcoin. More specifically, the VMA strategy with a one percent band overwhelms a strategy without one. Both the buy return and buy-sell difference is higher when the short period MA is based on a one- and two-minute MA. Overall, while significance hinders conclusive results through the use of the FMA strategy, buy signals are found to generate higher returns than sell signals in the VMA trading rule. These results support the conclusion that some technical rules can present evidence of predictive power, however, issues such as market liquidity and transaction costs must be further considered.

Therefore, future research could focus on extended technical trading analyses through: i) considering a wider set of cryptocurrencies; ii) incorporating trading costs (such as commissions paid to the exchange and bid-ask spreads) into the strategy; and iii) applying more complicated technical trading rules such as pairs trading and comparing the results. 
Table 4

Standard test results for the trading range break (TRB) rules.

\begin{tabular}{|c|c|c|c|c|c|c|c|c|}
\hline Holding Period & Test & N(buy) & $\mathrm{N}($ sell $)$ & Buy & Sell & Buy $>0$ & Sell $>0$ & Buy-Sell \\
\hline $10 \mathrm{~min}$ & $(1,10,0)$ & 779,910 & 744,126 & -0.0061 & 0.0132 & 0.3498 & 0.3454 & $-0.0193^{* * *}$ \\
\hline $20 \mathrm{~min}$ & $(1,20,0)$ & 822,760 & 776,840 & $-0.0094 * * *$ & 0.0210 & 0.3449 & 0.3422 & $-0.0304^{* * *}$ \\
\hline $30 \mathrm{~min}$ & $(1,30,0)$ & 840,630 & 794,910 & $-0.0124^{* * *}$ & $0.0243^{* * *}$ & 0.3421 & 0.3406 & $-0.0367^{* * *}$ \\
\hline $60 \mathrm{~min}$ & $(1,60,0)$ & 864,060 & 806,263 & $-0.0189^{* * *}$ & $0.0544^{* * *}$ & 0.3378 & 0.3390 & $-0.0733^{* * *}$ \\
\hline $90 \mathrm{~min}$ & $(1,90,0)$ & 874,350 & 804,360 & $-0.0294^{* * *}$ & $0.0764^{* * *}$ & 0.3372 & 0.3364 & $-0.1058^{* * *}$ \\
\hline $120 \mathrm{~min}$ & $(1,120,0)$ & 882,960 & 802,560 & $-0.0452^{* * *}$ & $0.0878^{* * *}$ & 0.3348 & 0.3353 & $-0.1330^{* * *}$ \\
\hline $180 \mathrm{~min}$ & $(1,180,0)$ & 892,377 & 797,220 & $-0.0455^{* * *}$ & $0.1001 * * *$ & 0.3370 & 0.3347 & $-0.1456^{* * *}$ \\
\hline $360 \mathrm{~min}$ & $(1,360,0)$ & 900,135 & 797,400 & $0.0105^{* * *}$ & $0.0983^{* * *}$ & 0.3397 & 0.3277 & -0.0878 \\
\hline $720 \mathrm{~min}$ & $(1,720,0)$ & 907,920 & 774,720 & $0.1223^{* * *}$ & $0.1070^{* * *}$ & 0.3441 & 0.3258 & 0.0152 \\
\hline $1440 \mathrm{~min}$ & $(1,1440,0)$ & 895,801 & 796,320 & $0.6122^{* * *}$ & $-0.1429 * * *$ & 0.3479 & 0.3196 & 0.7551 \\
\hline Holding Period & Test & N(buy) & $\mathrm{N}($ sell $)$ & Buy & Sell & Buy $>0$ & Sell $>0$ & Buy-Sell \\
\hline $10 \mathrm{~min}$ & $(1,10,0.01)$ & 6760 & 8560 & -0.1260 & $0.3225^{* * *}$ & 0.4272 & 0.4778 & $-0.4485^{* * *}$ \\
\hline $20 \mathrm{~min}$ & $(1,20,0.01)$ & 10,860 & 14,120 & -0.0806 & $0.2957 * * *$ & 0.4171 & 0.4522 & -0.3763 \\
\hline $30 \mathrm{~min}$ & $(1,30,0.01)$ & 14,070 & 18,780 & -0.0403 & 0.3460 & 0.4109 & 0.4368 & -0.3863 \\
\hline $60 \mathrm{~min}$ & $(1,60,0.01)$ & 20,940 & 29,940 & 0.0264 & 0.4299 & 0.3989 & 0.4143 & -0.4035 \\
\hline $90 \mathrm{~min}$ & $(1,90,0.01)$ & 27,090 & 37,800 & -0.0713 & 0.3563 & 0.3907 & 0.4105 & -0.4276 \\
\hline $120 \mathrm{~min}$ & $(1,120,0.01)$ & 31,920 & 45,360 & -0.0016 & 0.3418 & 0.3847 & 0.4108 & -0.3435 \\
\hline $180 \mathrm{~min}$ & $(1,180,0.01)$ & 41,040 & 59,940 & $-0.3073^{* * *}$ & $0.5246^{* * *}$ & 0.3802 & 0.4132 & -0.8319 \\
\hline $360 \mathrm{~min}$ & $(1,360,0.01)$ & 59,400 & 91,440 & $0.2204 * * *$ & $0.5398^{* * *}$ & 0.3785 & 0.4007 & -0.3194 \\
\hline $720 \mathrm{~min}$ & $(1,720,0.01)$ & 86,400 & 136,800 & $1.0173^{* * *}$ & $0.4608^{* * *}$ & 0.3723 & 0.3890 & 0.5565 \\
\hline $1440 \mathrm{~min}$ & $(1,1440,0.01)$ & 138,240 & 182,880 & $0.5280^{* * *}$ & $0.1750^{* * *}$ & 0.3717 & 0.3763 & 0.3530 \\
\hline
\end{tabular}

Note: 'N(Buy)' and 'N(Sell)' are the number of buy and sell signals reported during the sample. *** indicates statistically significance at the Bonferroni-adjusted $0.1 \%$ level respectively, testing the difference of the mean buy and mean sell from the unconditional $n$-minute mean, and buysell from zero.

\section{References}

Batten, J.A., Lucey, B.M., McGroarty, F., Peat, M., Urquhart, A., 2018. Does intraday technical trading have predictive power in precious metal markets? J. Int. Financ. Mark.Inst. Money 52, 102-113.

Bouri, E., Gupta, R., Roubaud, D., 2018a. Herding behaviour in cryptocurrencies. Finance Res. Lett. https://doi.org/10.1016/j.frl.2018.07.008. Article in Press

Bouri, E., Lau, C., Lucey, B., Roubaud, D., 2018b. Trading volume and the predictability of return and volatility in the cryptocurrency market. Finance Res. Lett. https:/doi.org/ 10.1016/j.frl.2018.08.015. Article in Press

Bouri, E., Shahzad, S., Roubaud, D., 2018c. Co-explosivity in the cryptocurrency market. Finance Res. Lett. https://doi.org/10.1016/j.frl.2018.07.005. Article in Press Brauneis, A., Mestel, R., 2018. Price discovery of cryptocurrencies: Bitcoin and beyond. Econ. Lett. 165, 58-61.

Brock, W., Lakonishok, J., LeBaron, B., 1992. Simple technical trading rules and the stochastic properties of stock returns. J. Finance 47 (5), $1731-1764$.

Corbet, S., Katsiampa, P., 2018. Asymmetric mean reversion of Bitcoin price returns. Int. Rev. Financ. Anal. https://doi.org/10.1016/j.irfa.2018.10.004.

Corbet, S., Larkin, C.J., Lucey, B.M., Meegan, A., Yarovaya, L., 2017. Cryptocurrency reaction to FOMC announcements: evidence of heterogeneity based on blockchain stack position. Available at SSRN 3073727.

Corbet, S., Larkin, C.J., Lucey, B.M., Yarovaya, L., 2019. Kodakcoin: a blockchain revolution or exploiting a potential cryptocurrency bubble? Appl. Econ. Lett. https://doi.org/10. 1016/j.frl.2018.07.010. Article in Press

Corbet, S., Lucey, B., Peat, M., Vigne, S., 2018a. Bitcoin futures: what use are they? Econ. Lett. 172, $23-27$.

Corbet, S., Lucey, B., Yarovaya, L., 2018b. Datestamping the Bitcoin and ethereum bubbles. Finance Res. Lett. 26, 81-88.

Corbet, S., Lucey, B.M., Urquhart, A., Yarovaya, L., 2018c. Cryptocurrencies as a financial asset: a systematic analysis. Int. Rev. Financ. Anal. https://doi.org/10.1016/j.irfa.2018. 09.003. Forthcoming, Available at

Corbet, S., Meegan, A., Larkin, C., Lucey, B., Yarovaya, L., 2018d. Exploring the dynamic relationships between cryptocurrencies and other financial assets. Econ. Lett. 165, 28-34.

Detzel, A. L., Liu, H., Strauss, J., Zhou, G., Zhu, Y., 2019. Bitcoin: Learning and Predictability via Technical Analysis. SSRN Working Paper.

Feng, W., Wang, Y., Zhang, Z., 2018. Informed trading in the Bitcoin market. Finance Res. Lett. 26, 63-70. https://doi.org/10.1016/j.frl.2017.11.009.

Gandal, N., Hamrick, J., Moore, T., Oberman, T., 2018. Price manipulation in the Bitcoin ecosystem. J. Monetary Econ. 95, 86-96.

Giudici, P., Abu-Hashish, I., 2019. What determines Bitcoin exchange prices? a network var approach. Finance Res. Lett. 28, 309-318. https://doi.org/10.1016/j.frl.2018.05.013. Griffin, J.M., Shams, A., 2018. Is Bitcoin really un-tethered? SSRN. Available at https://ssrn.com/abstract $=3195066$

Katsiampa, P., Corbet, S., Lucey, B., 2019. Volatility spillover effects in leading cryptocurrencies: a BEKK-MGARCH analysis. Finance Res. Lett. 29, 68-74. https://doi.org/10. 1016/j.frl.2019.03.009.

Liu, W., 2018. Portfolio diversification across cryptocurrencies. Finance Res. Lett. https://doi.org/10.1016/j.frl.2018.07.010. Article in Press

Marshall, B.R., Cahan, R.H., Cahan, J.M., 2008. Can commodity futures be profitably traded with quantitative market timing strategies? J. Bank. Finance 32 (9), 1810-1819.

Mensi, W., Al-Yahyaee, K., Kang, S., 2018. Structural breaks and double long memory of cryptocurrency prices: a comparative analysis from Bitcoin and ethereum. Finance Res. Lett. https://doi.org/10.1016/j.frl.2018.07.011. Article in Press

Mensi, W., Lee, Y.-J., Al-Yahyaee, K.H., Sensoy, A., Yoon, S.-M., 2019. Intraday downward/upward multifractality and long memory in Bitcoin and ethereum markets: an asymmetric multifractal detrended fluctuation analysis. Finance Res. Lett. https://doi.org/10.1016/j.frl.2019.03.029.

Nadarajah, S., Chu, J., 2017. On the inefficiency of Bitcoin. Econ. Lett. 150, 6-9.

Panagiotidis, T., Stengos, T., Vravosinos, O., 2018. On the determinants of Bitcoin returns: a lasso approach. Finance Res. Lett. 27, 235-240. https://doi.org/10.1016/j.frl.2018. 03.016.

Raj, M., Thurston, D., 1996. Effectiveness of simple technical trading rules in the hong kong futures markets. Applied Econ. Lett. 3 (1), $33-36$.

Sensoy, A., 2018. The inefficiency of Bitcoin revisited: a high-frequency analysis with alternative currencies. Finance Res. Lett. https://doi.org/10.1016/j.frl.2018.04.002. Forthcoming, Available at

Taylor, M.P., Allen, H., 1992. The use of technical analysis in the foreign exchange market. J. Int. Money Finance 11 (3), $304-314$.

Urquhart, A., 2016. The inefficiency of Bitcoin. Econ. Lett. 148, 80-82.

Urquhart, A., 2017. Price clustering in Bitcoin. Econ. Lett. 159, 145-148.

Vidal-Tomas, D., Ibanez, A., Farinos, J., 2018. Herding in the cryptocurrency market: cssd and csad approaches. Finance Res. Lett. https://doi.org/10.1016/j.frl.2018.09.008. Article in Press

Wei, W.C., 2018. Liquidity and market efficiency in cryptocurrencies. Econ. Lett. 168, 21-24. 